\title{
Do mito ao enigma: a história da arte como iconologia
}

\author{
Naiara dos Santos Damas Ribeiro
}

PANOFSKY, Erwin e Dora. A Caixa de Pandora: as transformações de um símbolo mítico. Tradução Vera Maria Pereira. São Paulo: Companhia das Letras, 2009 (Coleção História Social da Arte)

O fascínio exercido pelas personagens mitológicas clássicas é - mesmo numa cultura soterrada por novas e intrincadas mitologias como a nossa - um dado possível de ser afirmado sem grandes percalços. Das bocas mais incautas em mesas de botequim às discussões eruditas sobre as narrativas míticas, a mitologia compõe seguramente um patrimônio comum da cultura ocidental. Entre as figuras míticas, Pandora - considerada pela mitologia grega como a primeira mulher, a maldade em forma de beleza, ou o "belo mal" - aparece como uma das mais expressivas narrativas no repertório das interpretações sobre a vida humana, seus sofrimentos e esperanças. Da Antiguidade aos tempos atuais, passando por Erasmo, Voltaire e Goethe, esse mito animou diferentes leituras e representações artísticas, sendo um dos pontos centrais das interpretações míticas sobre a introdução do mal nos negócios telúricos. Presentes em esculturas, poemas, gravuras, pinturas e em peças teatrais que se dedicaram a explorar as diversas facetas desse mito ao longo de séculos, Pandora e sua "caixa" compõem certamente um curioso e complexo objeto de estudo. Entre os historiadores da arte e da cultura que se devotaram a este tema, destaca-se o casal Dora e Erwin Panofsky, com o livro $A$ Caixa de Pandora.

Publicada originalmente em 1956, esta obra ganhou as livrarias brasileiras apenas em 2009, numa edição ricamente ilustrada apresentada pela Companhia das Letras. Depois de mais de 50 anos de atraso, o leitor brasileiro poderia se perguntar: por que valeria a pena ousar, tal como Pandora no gesto de descerrar a famosa "caixa", abrir esse livro? Tantos anos depois de sua primeira publicação, o que traria de importante para o entendimento do mito de Pandora e para a história da arte de modo geral? A cada um dos leitores, de acordo com o tipo de interesse que dispensa ao tema, cabe responder a essas perguntas. Mas, seguramente, estamos diante de uma obra-prima de erudição que conjuga, com maestria, exame estilístico e perspectiva comparada, iluminando as inúmeras mudanças no cenário da historiografia da arte atual ao apresentar uma das tradições fundamentais na consolidação e desenvolvimento dos estudos culturais das imagens e dos símbolos.

A própria parceria entre Erwin Panofsky e sua esposa Dora torna essa obra ainda mais interessante. Casados desde 1916, após se conhecerem quando frequentavam o curso de História da Arte, em Berlim, compartilharam a carreira e o enorme sucesso intelectual e acadêmico de Erwin na Alemanha do período entre-guerras, assim como a mudança para os Estados Unidos, na década de 1930, quando da perseguição aos judeus pelo governo nazista. Apesar de sua promissora formação em História da Arte, Dora não pôde se doutorar. Mãe de dois filhos e companheira de um historiador com uma trajetória brilhante, Dora acabou por abdicar de sua carreira sem, contudo, abster-se de auxiliar nos trabalhos de Erwin e de continuar seus estudos com o historiador da arte Aby Warburg, em Hamburgo, na década de 1920. Mas foi somente aos 70 anos que Dora começou a publicar por conta própria e em parceria com o marido, como no caso do livro em exame. Como afirmam muitos comentadores, a escolha do mito de Pandora como objeto de investigação - além de contemplar os interesses de ambos pelas mutações de mitos e símbolos clássicos na arte através dos séculos - sugeria também uma curiosa anedota. Conhecido entre os amigos pela alcunha de "Pan", Erwin Panofsky e Dora cunharam a fórmula "Pan+Dora", parceria que se realizaria não apenas na vida conjugal, mas, igualmente, na vida intelectual, companheiros que foram até a morte de Dora em 1965, seguida pela de "Pan" em 1968.

O ponto de partida da obra do casal não deixa dúvida sobre o tipo de problema com que es- 
tão lidando: envolta por um "estranho fascínio", a personagem mítica Pandora - assim como acontece com muitos outros mitos - se manteve viva e forte até os nossos dias sem, contudo, permanecer incólume a diferentes entrelaçamentos, contornos, usos, interpretaçóes e significados ao longo de centenas de anos. Seja emprestando seu nome para apelidar rainhas inglesas e policiais franceses, seja como tema de um poema inacabado de Goethe ou de uma pintura pós-impressionista - como apontam os autores -, as diversas conotações associadas ao seu nome dão testemunho da longa e duradoura popularidade do mito de Pandora.

Ao invés de negar o fascínio da figura de Pandora, o casal Panofsky sucumbe a ele com o olhar erudito dos historiadores da arte preocupados em encontrar nas representações artísticas e literárias um vínculo profundo e essencial com a cultura. Não pretendendo oferecer uma monografia completa sobre o tema eles optaram, ao contrário, por seguir os rastros de alguns problemas específicos onde quer que estes pudessem levá-los à história das metamorfoses do mito. Suas implicações figurativas - em estátuas, peças de teatro, medalhas, logotipos editoriais, desenhos, pinturas, gravuras, poemas, bronzes, tapeçarias, afrescos - nas diversas versões contrastantes, na sua fortuna e também no seu desenvolvimento nos diversos ramos da cultura e no curso do tempo, mais precisamente na literatura e arte pictóricas europeias, da Antiguidade aos dias atuais, constituem, portanto, a proposta investigativa dos Panofsky. Todos esses caminhos seja a confusão entre as representações de Pandora e o mito romano de Psiqué, ou o paralelo estabelecido entre Eva e Pandora no Renascimento, ou, ainda, a imagem dessa personagem mítica na obra de Max Beckmann no século XX - conduziram o casal, contudo, a uma investigação mais profunda: interessava-lhes investigar as transformaçôes no modo como os seres humanos interpretavam e compreendiam o mundo no qual viviam.

Essa relação entre a arte e seu contexto de produção - em que a história da arte ilumina a história da cultura e vice-versa - é o ponto central do método iconológico proposto por Erwin Panofsky, sobretudo na década de 1930. Buscando ir além das perguntas sobre o caráter formal das obras de arte, ele defendia, com este método, que o interesse dos historiadores da arte deveria recair sobre o significado das formas artísticas e o conteúdo das imagens, atribuindo aos testemunhos figurativos o papel de fontes históricas para a investigação da cultura geral de um período. Em contraposição à crítica formalista da arte proposta por H. Wölffin em Conceitos fundamentais da história da Arte (1915) e A. Riegl em Questôes de estilo: fundamentos para uma história do ornamento (1893) - que pretendia excluir da análise das obras de arte tudo o que fosse alheio à obra em si mesma, concebendo-a como um objeto independente do contexto em que havia sido criada -, e seguindo os passos do historiador da arte alemão Aby Warburg, Erwin Panofsky propunha, portanto, uma interpretação cultural da forma artística.

Como método de interpretação das imagens e dos objetos artísticos, a iconologia incluía em sua démarche investigativa três níveis de interpretação distintos, embora complementares, tal como E. Panofsky havia sistematizado em seu livro O significado nas artes visuais, em 1955, isto é, um ano antes da publicação de $A$ Caixa de Pandora. O primeiro nível, o pré-iconográfico, dizia respeito à identificação por familiaridade, constituindo-se nas impressões iniciais despertadas pelo objeto em questão; o segundo, a iconografia, era o momento da identificação dos motivos artísticos com temas, conceitos ou significados convencionais, tal como encontrados em fontes literárias e/ou orais de determinada tradição cultural; por fim, o terceiro nível era propriamente o da interpretação iconológi$c a$, quando o significado intrínseco era apreendido por meio do cruzamento desses motivos com as inclinações, expectativas e interesses de uma tradição, comunidade ou época. Era neste último nível interpretativo, momento final da iconologia, que os motivos artísticos identificados pela iconografia adquiriam o estatuto de valores simbólicos, de configuraçôes que expressavam sinteticamente uma complexa urdidura de sentidos, capaz, por sua vez, de permitir o acesso ao mundo cultural que deu lugar à produção do objeto artístico.

Essa démarche crítica - que partia da imagem, metamorfoseando-a em símbolo, para então elevála à condição de sintoma cultural - era, como já afirmava Aby Warburg, um trabalho similar àque- 
le do detetive. Fundado no empenho de decifrar as fontes figurativas partindo das formas evidentes aos sentidos subjacentes, das intenções expressas às motivações e propósitos involuntários, este trabalho era caracterizado tanto pelo interesse em relação à dimensão cultural do objeto artístico, quanto pelas suas condicionantes antropológicas, sendo ambos determinados pela historicidade do objeto. Em outras palavras, nessa história social da arte importava perceber como determinados valores expressivos da cultura - como motivos, alegorias, conceitos, mitos etc. - se cristalizavam em formas artísticas, e quais as razóes que determinavam sua transformação ao longo do tempo.

Este programa investigativo - proposto por Aby Warburg e ao qual se dedicaram muitos dos pesquisadores ligados ao Instituto Warburg, tal como o próprio E. Panofsky, Ernst Cassirer, Fritz Saxl, entre outros - concebia as imagens como símbolos condensadores de uma memória coletiva que circulariam através do tempo, reativandose e modificando-se ao inserirem-se em momentos históricos específicos. Partindo de uma concepção de tempo não linear, esse processo de transmissão e transformação das imagens não era tomado, contudo, de forma evolutiva e abstrata, tal como na investigação dos "estilos artísticos", mas sim como expressão de um "fenômeno diacrônico complexo" em que o passado sobrevivia no presente como temporalidade nunca efetivamente concluída. Como "permanência" no presente, o passado serviria, então, como repertório de possibilidades que atuaria na condição de guia em determinadas escolhas a serem feitas, seja na arte e na ciência, assim como em outras esferas da atividade humana.

A história do mito de Pandora na tradição ocidental segue, em grande medida, esse itinerário. Nascida na Antiguidade e revivida no Renascimento - para então ser constantemente refigurada - , as transformações sofridas por essa personagem mítica compõem um exemplo desse complexo movimento de sobrederterminação temporal da história em que o passado emerge no presente através de valores expressivos recorrentes, como a própria estrutura da obra sugere.

Nos dois primeiros capítulos, o casal Panofsky discute as origens gregas do mito de Pandora em
O trabalho e os dias, do poeta Hesíodo, e sua fortuna na tradição latina, passando pela Idade Média, até chegar ao Renascimento, quando a personagem ressurge, sobretudo em território francês, após um relativo esquecimento. Nesse percurso, contudo, uma curiosa metamorfose teria ocorrido, como afirmam os autores. A partir de um mal-entendido, o objeto que acompanhava essa personagem no poema de Hesíodo - um jarro (pithos ou dolium) de onde teria saído todos os males que a humanidade haveria de herdar - transforma-se na caixa (pyxis) proibida trazida por Pandora à terra, dando origem à expressão "caixa de Pandora", tão comum nas representações modernas deste mito.

Mas qual seria a origem desse mal-entendido? Para o casal Panofsky foi o "acidente filológico" cometido pelo humanista Erasmo de Rotterdam em sua obra do século XVI, Adagiorum chiliades três, que determinou a fortuna do mito de Pandora ao longo dos séculos, apesar da aparente insignificância do erro. É provável, defendem os autores, que Erasmo tivesse fundido, ou confundido, o episódio crucial da vida de Pandora, narrado por Hesíodo, com sua réplica quase idêntica na literatura romana, a Psiqué de Apuleio. Seja como for, a partir daquele momento, em quase todas as línguas europeias, as expressões relativas à "caixa de Pandora" foram aceitas idiomaticamente "como denominação da fonte dos mais diversos desastres", sendo usadas "como título de muitas peças de teatro e romances que giram em torno de um exemplar atraente, mas destrutivo do gênero feminino" - tal como afirma o casal Panofsky.

Apesar de portadora de um atributo inautêntico, a pyxis, Pandora continuou seu caminho pelo século XVI europeu ganhando novos contornos e significados, tendo se transformado numa personagem francesa por excelência. Do terceiro ao sexto capítulo - quando o casal Panofsky trata da representação de Pandora na obra de pintores, como Andrea Alciati, Rosso Fiorentino e Jacques Callot - podemos acompanhar como o mito grego do "belo mal" transformou-se numa personagem viva que apelava à imaginação de artistas renascentistas. Ainda nesse século, Pandora, a figura pagã da primeira mulher, se associou à imagem cristã de Eva, à alegoria da Esperança representada 
com o aspecto de um corvo - ainda não identificado como agente, ou arauto, de ameaças e infortúnios - e à representação do banimento da Ignorância. Neste último aspecto, a conotação negativa do ato de abrir a "caixa" - como impensado, portanto, perigoso - foi substituída por uma positiva, pelo louvor à salutar curiosidade de Pandora.

Sem grande apelo no século XVII, o mito de Pandora teve que aguardar até o final do século XVIII para encontrar outro momento de vigor, como podemos observar no oitavo capítulo, quando Dora e Erwin Panofsky oferecem ao leitor observações penetrantes sobre o Classicismo romântico nos quadros da crítica de arte erudita na Inglaterra. Nesse contexto, como assinala o casal, o próprio feitiço da tradição erasmiana foi contestado e empreendeu-se um esforço em devolver à "caixa" de Pandora sua forma correta, no interior de uma tendência mais ampla de "recuperar o passado mediante uma reconstrução científica". No século XIX, porém, o casal Panofsky afirma que "o idioma triunfou sobre a arqueologia" e a "caixa" atribuída por Erasmo à Pandora se consolidou como a representação convencional do mito, vindo mesmo a predominar como uma espécie de "hieróglifo independente" nas representaçōes de pintores pós-impressionista no século XX, como Paul Klee e Max Beckmann.

$\mathrm{Na}$ literatura, sobretudo nas peças teatrais, de Calderón a Goethe, o mito de Pandora passou por um processo de transformação peculiar, tal como nas artes pictóricas. E este é o tema do Epílogo da obra. Dissociada do teor pessimista presente no poema de Hesíodo, Pandora sobe ao palco no teatro setecentista de Calderón, segundo o casal Panofsky, sob uma ótica positiva. Como manifestação visível e tangível da deusa Minerva, a peça de Calderón apresentava Pandora como a "manifestação” de um conceito abstrato e filosófico que representava a união entre a mente humana criativa e a encarnação enobrecedora da arte e da ciência. Nesta mesma chave de leitura positiva do mito, Goethe no século XVIII, em seu poema inacabado, fez com que Pandora, embora simbolizasse o princípio da submissão dos homens às necessidades físicas e à influência perturbadora dos sentidos, representasse, igualmente - e pelo mesmo princípio - a parcela de beleza concedida ao corpo humano e a habilidade para a prática de artes e ofícios.

O exemplo da obra de Goethe e o seu entrelaçamento peculiar com a tradição da Antiguidade tardia representam para o casal Panofsky mais do que apenas um momento no percurso de Pandora na cultura ocidental. A interpretação do mito pelo poeta alemão revela, segundo os autores, "que até o maior dos mortais - como foi Goethe para a tradição ocidental - não se assemelha a Deus, que criou do nada, porque precis[ou] 'manipular materiais previamente existentes". E essa é a trama a partir da qual nasce $A$ Caixa de Pandora de Erwin e Dora Panofsky: são os entrelaçamentos, as escolhas, as tensões, os cruzamentos inusitados, as sobreposições e até mesmo os equívocos o que fazem girar o motor que engendra a arte e a história no complexo movimento pendular em que o passado e o presente se encontram para perpetuar a cultura como espaço e criação do humano.

Dessa forma, se é para Pandora que Erwin e Dora Panofsky dirigem sua intenção interpretativa - aspirando dar sentido às multifacetadas versões sobre este mito -, seu objetivo, contudo, está para além da personagem: refazer as peregrinaçōes desse mito na arte e na literatura ocidentais significa, em grande medida, iluminar momentos importantes da história dessa cultura criando a si mesma. E, da mesma forma com que os artistas estudados pelo casal Panofsky recorrentemente convidavam Pandora a entrar em cena em suas obras, também PanDora atuaram na cadeia de revitalização e transformação dessa personagem mítica em mais um capítulo de sua curiosa jornada pelo mundo da cultura. E certamente virão outros. 